\title{
Discussion on Core Technique and General Software Platform of River Water Resources Regulation in China
}

\author{
Zhiguo Gan ${ }^{1, \mathrm{a}}$, Siyu $\mathrm{Cai}^{1}$ and Xianhao $\mathrm{He}^{2}$ \\ ${ }^{1}$ China Institute of Water Resources and Hydropower Research, Beijing, 100038, China \\ ${ }^{2}$ Urumqi No.1 Senior High School, Urumqi, 830002, China
}

\begin{abstract}
Due to the aggravation of human activities and global climate changes in recent decades, catchment water cycle has experienced strong variation. The world is faced with profound water crisis, and water problems are especially severe and water disasters are of high frequency in China. Water problems have become significant obstacle factors for realizing sustainable development, which greatly threatens national economy and ecological safety. Given the scientific background of catchment water cycle evolution and water resources comprehensive regulation, we propose the method of solving water problems through water resources operation based on dualistic water cycle theory and discuss the developing status and existing problems of current water resources operation in China. On this basis, we also put forward the technical framework and key process of water resources regulation, which integrates the six links of monitoring, simulation, evaluation, forecasting, regulation and control. Furthermore, aiming at the background of the second phase of National Water Monitoring Capacity Building Project, we introduce a nationwide general software platform for water resources regulation. This platform will realize business collaboration and information sharing among three-scale platform of Ministry of Water Resources, basin authorities and provincial level, so as to overall improve the ability of water resources regulation and decision-making.
\end{abstract}

\section{INTRODUCTION}

\subsection{Water Problems in China}

Due to the aggravation of human activities and global climate changes in recent decades, catchment water cycle has experienced strong variation, such as resource decay, environmental pollution, ecological degradation, supply and demand imbalance, groundwater overdraft and so on. Water problems have seriously threatened the national economy and ecological security. In China, water problems are especially severe; flood, drought, pollution and ecological degradation coexist, and water disasters occur frequently. The major problems are as follows:

(1) Water resources shortage. The national water shortage is 50 billion square meters in normal years. Water shortage is severe in Hai River, Yellow River, Liao River, Northwest China and eastern coastal cities, and the scope of shortage is extending.

(2) Water pollution. China's waste water discharge is 747 billion square meters in 2009, the standard rate of surface water functional area is only $47.4 \%$, and the percentage of monitor well with water quality in IV $\sim \mathrm{V}$ class reaches $72.1 \%$.

(3) Water ecological degradation. Although the freshwater ecosystem is improved locally, the system overall emerge a degradation trend. Besides, the groundwater is seriously over-exploited in North plain areas, resulting in 160 overdraft areas.
(4) Increasing frequency of extreme and sudden events. Drought disasters occur frequently in North China recently, and seasonal drought events is on the rise in southern rainy regions, while the occurring frequency of sudden water pollution accidents is increasing.

\subsection{Scientific Bases of Water Problems}

Water resources is forming and evolving in the process of catchment water cycle, so the scientific bases of water resources regulation are catchment water cycle evolution and water resources comprehensive regulation. The recognition and simulation of catchment water cycle is therefore becoming the precondition of reasonable water resources regulation.

Since the middle of the 20th century, studies on catchment water cycle and water resources comprehensive regulation under the background of changing environment has been carried out widely at home and abroad ${ }^{[1-2]}$. With the social development, water usage is increasing, so the artificial water cycle with four basic links of water withdraw, water transfer, water usage and water recession is formed. Artificial water cycle and natural water cycle make up the dualistic water cycle ${ }^{[3]}$.

With the increasing intensity and extensity of human activities, the influence on natural water cycle is gradually growing and the duality is more distinct ${ }^{[4-6]}$. On one hand, human activities change the structure and circulation path of water system through direct actions such as reservoir,

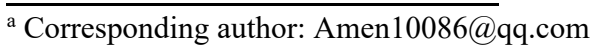


water diversion project and artificial water usage; on the other hand, through indirect methods, for example, deforestation, land utilization and greenhouse gas emission, underlying surface and regional climate has been changed so as to impact elements of water cycle ${ }^{[7]}$. In a word, basin or regional water recharge and consumption has greatly changed in this process, and water pollution and environmental pollution aggravate at the same time. Therefore, studies on water resources regulation based on dualistic water cycle is the solution to the water problems

\section{WATER RESOURCES REGULATION RESEARCH}

\subsection{Research Status of Water Resources Regulation8.58}

Water resources regulation research originates from the reservoir optimal operation problem proposed by Masse in 1940s. System engineering was established in the middle of 1950s and was widely applied in reservoir group optimal operation. In 1980s, "Scientific Distribution of Water Resources" written by N.Buras studied the allocation theory and methods of water resources regulation ${ }^{[8]}$. Water resources research in China starts relatively late, but develops fast. China began water resources allocation studies in the 1960 s, led by reservoir optimal operation, and the deep research started from the 80s. Before 1990s, research was mainly focused on reservoir scheduling for beneficial use and interbasin water transfer, which didn't take ecological water within the river channel into consideration. Since 2000, China has put more emphasis on river ecological water and carried out uniform water scheduling and ecological water compensation works. Currently, catchment water resources management and regulation in China has been preliminarily formed, and is becoming more mature in terms of scheduling rules, methods and technologies ${ }^{[9]}$.

\subsection{Water Resources Regulation Problems in China}

In recent years, China's water resources scheduling has made great progress, and has played a prominent role in maintaining sustainable economic and social development, building and restoring ecological environment. Looking at the history of water resources regulation research, early and medium studies mainly focused on how to establish scheduling model and solution model, focusing on theoretical research. In recent 10 years, theoretical research has been increasingly mature and perfect, a lot of achievements appeared, but application was less, failing to form a practical and mature methods of scheduling. The main questions are as follows:

(1) Lack of basic research. For example, "NaturalArtificial" dualistic water cycle simulation and regulation theory, flood forecasting uncertainties and risk scheduling of water resources system, solutions and coordination mechanism of multi-objective problems.
(2) Lack of practicality. Early and medium studies mainly focused on how to establish scheduling model and solution model, focusing on theoretical research. The combination with practice is undertighten, which is failure to play the role of theoretical guidance.

(3) Poor productization of models and software. Water resources system simulation and model development are mainly focused on researches. It has not formed a series of hydraulic professional model software products with all independent intellectual property rights and certain scales. We need to purchase a large number of model software from abroad each year.

Aimed at the above questions, this paper proposed a core technique system of water resources regulation in terms of three-dimensional monitoring of water resources, dualistic water cycle simulation, dynamic evaluation of water resources, real-time forecasting, water resources regulation and hydraulic control. In addition, a nationwide general software platform for water resources regulation was developed and applied in different catchments.

\section{CORE TECHNIQUE OF WATER RESOURCES REGULATION}

\subsection{Technical Framework}

Water cycle simulation and regulation in a basin or region can be divided into six stages: monitoring, simulation, evaluation, forecasting, regulation and control (Fig.1). The four links of monitoring, simulation, evaluation and forecasting are focused on the whole process of basin/regional "Natural-Artificial" dualistic water cycle. While regulation and control are aimed at the facing period, through the comprehensive regulation of water quality and quantity, surface water and groundwater, control of safety and operation, so as to realize catchment dualistic water cycle. 


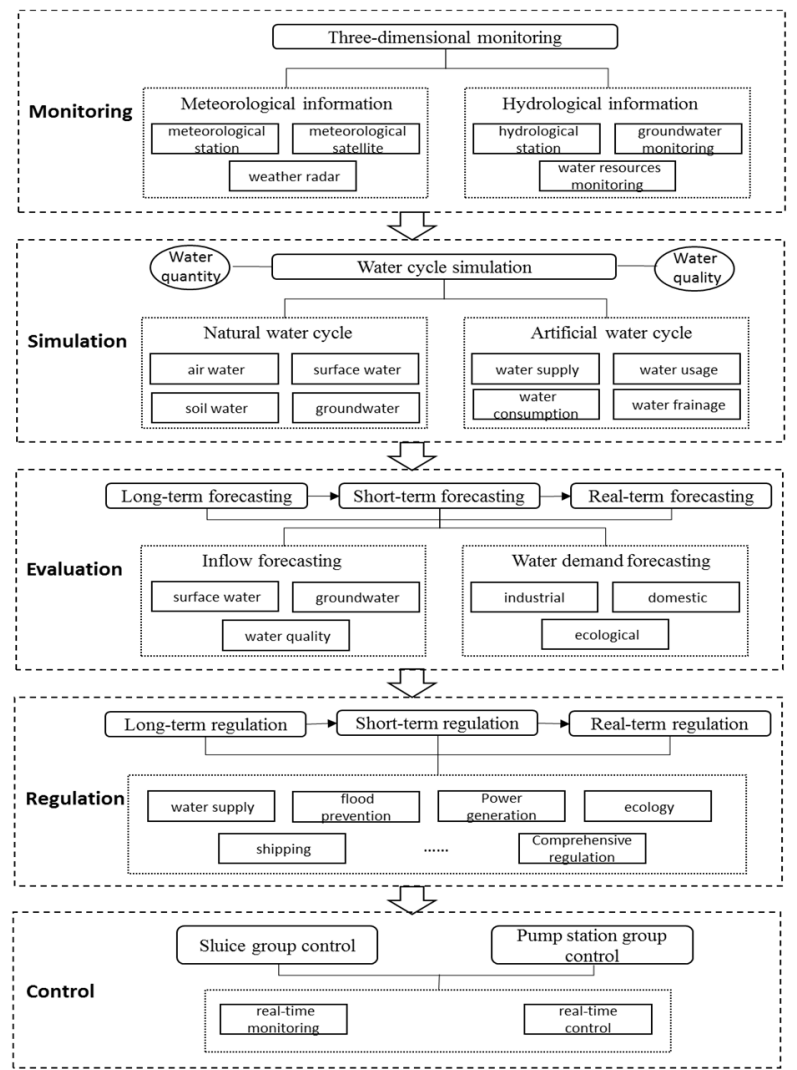

Figure 1. Technical framework of water resources regulation

\subsection{Three-dimensional Monitoring}

Traditional hydrological monitoring is based on traditional hydrological theory, whether network distribution or monitoring method is built based on the natural property of water ${ }^{[11]}$. With the global changing and human activities, the "natural-artificial" dualistic characteristics of water resources evolution is becoming obvious, the traditional monitoring method cannot satisfy the need of modern water resources development, management and protection. It is necessary to consider the integrity of water cycle and the property of nature, society, economy, environment and ecology ${ }^{[12]}$.

Recently, remote sensing monitoring technology is developing dramatically, which overcomes the shortage of traditional surface observation, such as limited ranges and discontinuous spatial distribution. Besides, combined remote sensing technology with traditional ground station monitoring, we are developing the three-dimensional monitoring system integrated with meteorology, hydrology and water resources.

\subsection{Dualistic Water Cycle Simulation}

Three-dimensional monitoring is the most direct and important measure to grasp water cycle system status and flux. However, just depending on monitoring can only obtain information of discrete part of space. It is therefore necessary to use simulation model to assimilate information of water quantity, water quality, surface water and groundwater, so as to form the description of the whole process of dualistic water cycle system. The simulation model usually include water resources system simulation model for artificial water cycle, distributed hydrological model for natural water cycle, hydrodynamic-water quality model for rivers, lakes and reservoirs, groundwater simulation model and so on. Model input should involve manual decision and control of water projects, in addition to natural meteorological and hydrological boundaries.

\subsection{Water Resources Dynamic Evaluation}

Through the two-way fusion and assimilation of monitoring, statistics and simulation, a detailed description of the whole process of the four-dimensional panoramic water cycle can be obtained. In order to facilitate water resource managers to manage the flux and state of water, we need to use big data analysis method to generate statistical index such as water resources quantity, quality, development and utilization based on simulation results. In addition, through excavating the mutual feedback mechanism between elements and processes of dualistic water cycle, it can be used to provide support for decision-making of water resources forecasting, regulation and control.

\subsection{Real-time Forecasting}

Based on the flux and state information of basin/regional dualistic water cycle, it is necessary to carry out long, mid and short-term forecasting of water resources and forecast future development tendency of water system. The object of long-term forecasting (annual/monthly) is to grasp water quantity and its overall changing trend. The midterm forecasting (1-10 days) has a certain accuracy, which can be reference for water resources allocation decisionmaking. The short-term forecasting (1-3 days) has high accuracy and can be used to guide water resources allocation.

\subsection{Water Resources Comprehensive Regulation}

The basic of water resources comprehensive regulation is the "Three Red Lines Control Index" of the most stringent water resources. In each scheduling year, we need to determine total water consumption of surface water and groundwater in each region and different industries. On this basis, this paper focuses on the annual allocation of water for important rivers and making scheduling schemes of important water conservancy projects along the river, which eventually forms the water flow scheduling scheme of the river. The control of total consumption of surface water and groundwater is the assessment target, and the water flow scheduling is the means to control the total water consumption of surface water. In addition, the scheduling schemes of important groundwater mining and complementary projects can also be formulated according to the requirements of normal and emergency water resources management.

\subsection{Hydraulic Control}


Hydrological forecasting provides the upstream and downstream boundary of optimal operation. Water project group regulation mainly involve regulation of reservoir, water diversion project and flood storage and detention zones, which provides hydraulic control objects (water quantity, water quality and water level) for the main buildings (sluice, pump station and hydropower station) of the three types of projects. In order to realize these hydraulic control objects, based on remote control and local control technology, the control instructions of gate, pump station, power station, rotation speed, etc. are required to be sent to the executing agency.

\section{GENERAL SOFTWARE PLATFORM OF RIVER WATER RESOURCES REGULATION}

\subsection{Background}

Current water resources regulation mainly depends on engineers' experience, but lacking scientific guidance and overall consideration. It is therefore necessary to build a decision support system for basin/regional water resources regulation to improve regulation level. According to the requirement of "National Water Resources Monitoring Ability Construction" Project, the main purposes include completing water resources monitoring system, completing operating environment construction of water resources monitoring management, completing development of application system and water resources monitoring system construction of important catchments.

In order to avoid iterative development of core modules of water resources normal and emergency regulation and improve the capability of maintenance and optimization upgrading of regulation models and business logics, a general water resources regulation software framework was developed based on the collection and analysis of common demands for water resources regulation and emergency management. It can provide a customizable, secondary developed and extensible software framework for the three-level platform (MWRBasin-Province). Meanwhile, this general software platform can realize business collaboration and information sharing of water resources regulation schemes among the three-level platforms, so as to improve the decision-making ability of national water resources regulation.

\subsection{Software Framework}

The framework of General Software Platform of River Water Resources Regulation is composed of 5 layers, 2 security systems and 4 types of service objects. The 5 layers include computer network layer, hardware facility layer, data resource layer, application support and business application layer; the 4 types of service objects are water resources management department of MWR, basin/provincial water resources management department, sub-provincial water resources management department and technical support department; the 2 security systems involve information security system and standard specification system (Fig.2). The details are as follows:

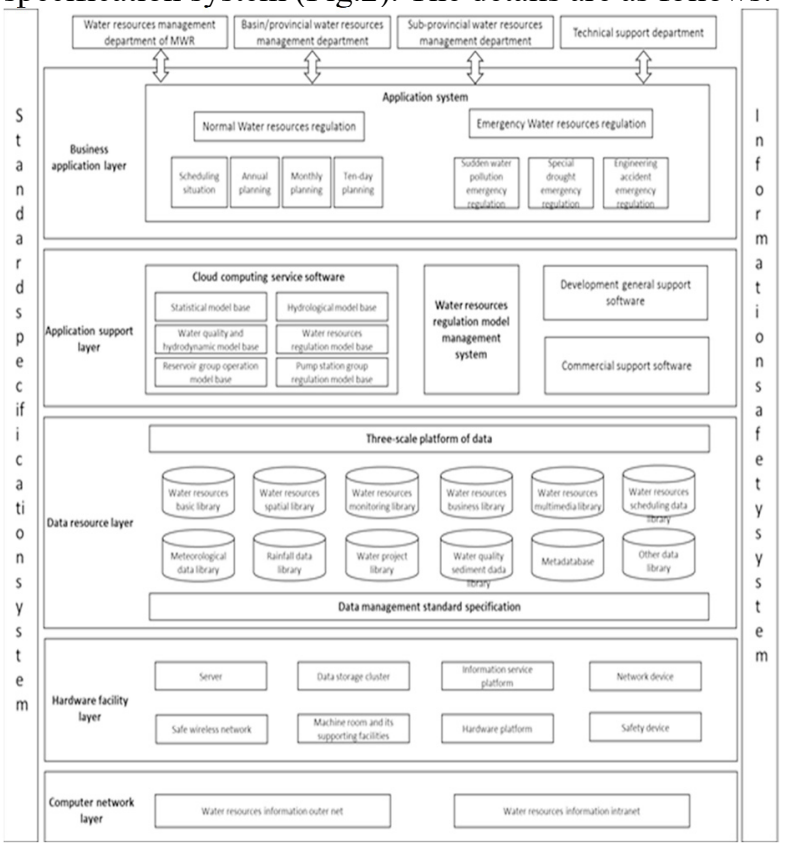

Figure 2. Overall architecture of General Software Platform of River Water Resources Regulation

(1) Application systems. The application systems consist of water resources component library and prototype system of General Software Platform of River Water Resources Regulation.

(2) Model Management System. It is used to build models which satisfies requirements of water resources regulation, including collection of hydrological data, generalization diagram of water resource scheduling, the default model warehouse, model management and model system management.

(3) Cloud computing service software. Cloud computing service is aimed to access all kinds of models developed according to the standard input/output interface and network interface, to conduct unified management and maintenance of accessed models and provide cloud computing services. The main functions of cloud computing service include model management, model performance management, model computing node management, model computing task service and model base.

(4) Database design. According to the business functions of the General Software Platform of River Water Resources Regulation, database is designed as model management library table, normal regulation library table, emergency regulation library table, cloud computing service library table and system management library table.

\subsection{Software Functions}

General Software Platform of River Water Resources Regulation provide functions such as water resources regulation situation, water resources normal regulation and water resources emergency regulation. This platform can increase efficiency of normal and emergency regulation, support the smooth expansion of the water 
resources dispatching business of the department of water resources, the river basin and the province, realize the operational synergy and information sharing between the three levels of the water resource scheduling schemes, so as to comprehensively improve the capacity of agencies at all levels to manage water resources and deal with emergencies (Fig.3)

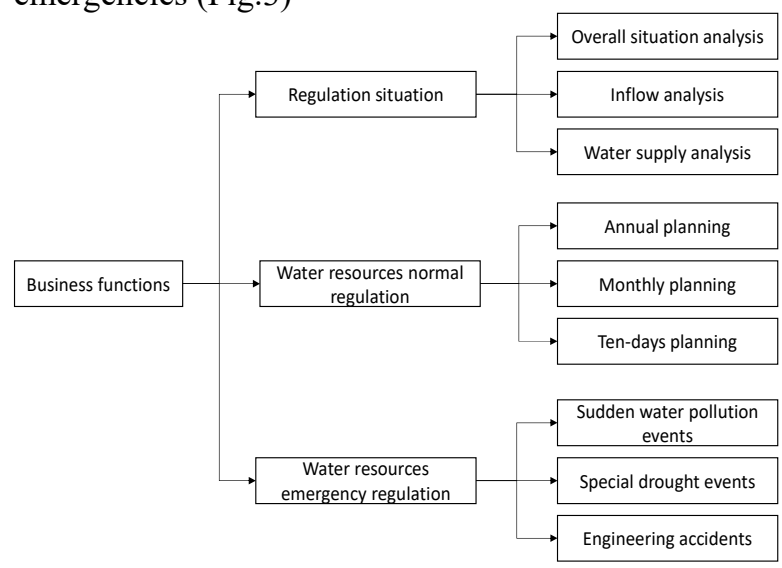

Figure 3. Functional framework of General Software Platform of River Water Resources Regulation

1)Water Resources Regulation Situation

Mainly provide the demonstration and analysis function of information needed for water resource scheduling, including overall situation analysis, inflow analysis and water supply analysis.

2)Water Resources Normal Regulation

According to current water resources situation, normal regulation scheme will be made through forecasting future incoming flow, mainly including model management, annual/monthly/ten-days water resources scheduling planning.

3)Water Resources Emergency Regulation

When sudden emergency accident happens, by tracing the causes of emergency events, the scheduling plan is prepared in combination with pre-arranged plan, and the emergency management plan is finally formulated through the consultation meeting. It mainly involve emergency scheduling planning for sudden water pollution events, special drought events and engineering accidents.

\section{Acknowledgements}

This paper was jointly supported by National Key R\&D Program (2017YFC0405105).

\section{References}

1. Barnett TP, Pierce DW, Hidalgo HG, Bonfils C, Santer BD, Das T et al., "Human-induced Changes in the Hydrology of the Western United States," Science, 2008, 319(5866):1080-1083

2. T Oki, S Kanae, "Global Hydrological Cycles and World Water Resources," Science, 2006, 313(5790): 1068.

3. Yuansheng P, Yong Z, Jianhua W. "Basin Water Resources Real-time Allocation: Case Study in the
Hehei River Basin," Advances in Water Science. 2006, 03: 395-401.

4. Hao W, Jianhua W, Dayong Q, "Theoretical Method of Water Resources Assessment Based on Dualistic Water Cycle," Journal of Hydraulic Engineering, 2006,37:1496-1502.

5. Ali U K, Ayhan E, Sukriye O, "Possible Impacts of Climate Change on Soil Moisture Availability in the Southeast Snatolia Development Project Region (GAP): An Analysis from an Agriculture Drought Perspective," Climate Change, 1998,40:3-4.

6. Wiberg D A, Kenneth M, "The Impact of Climate Change on Regional Surface Water Supply from Reservoirs Storage in China," In: Proceedings of the 1st International Yellow River Form on River Basin management, 2003 Oct 21-23, Zhengzhou. Zhengzhou: Yellow River Conservancy Publishing House, 2003. 248-266.

7. Dayong Q, Chuiyu L, Jiahong L, "The Framework of Basin "Natural-Artificial" Dualistic Water Cycle Theory," Chinese Science Bulletin, 2014(Z1):419427.

8. N.Buras, "Scientific Distribution of Water Resources," 1983.

9. Kun D, Xuan Z, Yongsheng Y, "Overview of Basin Water Resources Regulation Research," Journal of Economics of Water Resources, 2011, 29(6):23-27.

10. Zhiguo C, Guangqian W, Wenbin W, "Study on Water Allocation Scheme Programming of Yellow River," The National First Symposium on Water Problem Research, Wuhan: Hubei Science \& Technology Press, 2003:308-315.

11. Zuo W and Hui H, "Construction and Development of Hydrological Station Network in China," Hydrology, 2006,26(3):42-44.

12. Denghua Y, Baisha W, Hao W, Dayong $Q$ and Xiangde X, "Water Resources Stereo Monitoring System for Water Source Region in West Route Water Transfer Project in China," Chinese Journal of Population Resources and Environment, 2010 (12):122-128.

13. Zhidan $\mathrm{H}$, Hang $\mathrm{Z}$ and Zhongjing $\mathrm{W}$, "Water Allocation Evolution in Yellow River and Multi-data Flow Model Analysis," ournal of Hydroelectric Engineering, 2015(8):35-43.

14. Bingyan C, "Technical Practice and Effects of Water Allocation in Heihe River Basin," Water Resources and Hydropower Engineering, 2003(1):41-43.

15. The People's Government of Xinjiang Uygur Autonomous Region, Ministry of Water Resources, "Recent Comprehensive Management Planning Report of Tarim River Basin," Urumchi: The People's Government of Xinjiang Uygur Autonomous Region, 2001.

16. Zhengjie $\mathrm{Y}$, Wei $\mathrm{H}$ and Jin $\mathrm{C}$, "Issue on Water Quantity Operation of Large Sized Reservoir in the Yangtze River Basin," Journal of Yangtze River Scientific Research Institute, 2011(7):7-12,18. 